\title{
Design of the Novel Protraction Mechanism of Insulin Degludec, an Ultra-long-Acting Basal Insulin
}

\author{
lb Jonassen • Svend Havelund $\cdot$ Thomas Hoeg-Jensen $•$ Dorte Bjerre Steensgaard • Per-Olof Wahlund • Ulla Ribel
}

Received: 25 October 2011 / Accepted: 12 March 2012 / Published online: 7 April 2012

(C) The Author(s) 2012. This article is published with open access at Springerlink.com

\begin{abstract}
Purpose Basal insulins with improved kinetic properties can potentially be produced using acylation by fatty acids that enable soluble, high-molecular weight complexes to form postinjection. A series of insulins, acylated at B29 with fatty acids via glutamic acid spacers, were examined to deduce the structural requirements.
\end{abstract}

Methods Self-association, molecular masses and hexameric conformations of the insulins were studied using size exclusion chromatography monitored by UV or multi-angle light scattering and dynamic light scattering, and circular dichroism spectroscopy (CDS) in environments (changing phenol and zinc concentration) simulating a pharmaceutical formulation and changes following subcutaneous injection.

Results With depletion of phenol, insulin degludec and another fatty diacid-insulin analogue formed high molecular mass filament-like complexes, which disintegrated with depletion of zinc. CDS showed these analogues adopting stable $T_{3} R_{3}$ conformation in presence of phenol and zinc, changing to $T_{6}$ with depletion of phenol. These findings suggest insulin degludec is dihexameric in pharmaceutical formulation becoming multihexameric after injection. The analogues showed weak dimeric association, indicating rapid release of monomers following hexamer disassembly.

Conclusions Insulins can be engineered that remain soluble but become highly self-associated after injection, slowly releasing monomers; this is critically dependent on the acylation moiety. One such analogue, insulin degludec, has therapeutic potential.

I. Jonassen $(\bowtie) \cdot$ S. Havelund · T. Hoeg-Jensen • D. B. Steensgaard • P.-O. Wahlund $\cdot \cup$. Ribel

Diabetes Research Unit, Novo Nordisk

Novo Nordisk Park

2760 Måløv, Denmark

e-mail: ibjo@novonordisk.com
KEY WORDS acylated insulin · basal insulin · insulin analogue $\cdot$ insulin degludec $\cdot$ insulin hexamer

$\begin{array}{ll}\text { ABBREVIATIONS } \\ \text { CDS } & \text { circular dichroism spectroscopy } \\ \text { DLS } & \text { dynamic light scattering } \\ \text { HPLC } & \text { high performance liquid chromatography } \\ \text { HSA } & \text { human serum albumin } \\ \text { MALS } & \text { multi-angle light scattering } \\ \text { MW } & \text { molecular weight } \\ \text { PD } & \text { pharmacodynamic } \\ \text { PK } & \text { pharmacokinetic } \\ \text { R } & \text { relaxed } \\ \text { RI } & \text { refractive index } \\ \text { SEC } & \text { size exclusion chromatography } \\ \text { T } & \text { tense }\end{array}$

\section{INTRODUCTION}

Insulin analogues have been used clinically since the late 1990s. The reason why human insulin is modified for exogenous subcutaneous injection therapy is to produce absorption kinetics that better match the rate of supply from the injection depot to dynamic physiological need (1).

Naturally, insulin self-associates into dimers, three of which will combine with two zinc ions to form a hexameric complex, believed to be an adaption to maximise storage within beta-cell vesicles $(1,2)$. With exocytosis (and subsequent dilution) these hexamers rapidly dissociate into biologically active monomers. When insulin is formulated for clinical use, however, a tolerable injection volume requires a concentration at which insulin is naturally hexameric. Thus, pharmaceutical preparations of 
insulin are injected as hexamers, which are too large to readily pass through capillary fenestrae, but the insulin eventually dissociates within the injection depot to be absorbed into the circulation, primarily as dimeric or monomeric units (2). The first insulin analogues were designed to have weaker selfassociation properties to allow more rapid absorption to coordinate the rise in plasma insulin levels with postprandial glucose absorption (3).

In the case of basal insulin development, the challenge has been to retard absorption to a greater extent than occurs with human insulin - ideally to produce a constant, peakless kinetic profile that mimics normal basal insulin secretion. The products currently available for clinical use achieve their prolonged action through a variety of mechanisms, including poorly soluble insulin-protamine (NPH insulin) or high zinc formulations (Lente insulin), $\mathrm{pH}$ dependent precipitation (insulin glargine) and local albumin binding (insulin detemir) (4). Although these mechanisms prolong the absorption kinetics of these products compared to regular human insulin, none give an ideal absorption profile. The original human insulin-based products, such as NPH insulin, had suboptimal pharmacokinetic (PK) profiles, characterised by inappropriate peaks of action coupled with high variability from injection to injection, both of which can lead to hypoglycaemia and oblige twice-daily dosing $(1,5,6)$. The two available insulin analogues (glargine and detemir) have improved profiles (5), but rising glycaemia during the day-time, seen especially when they are used with rapid-acting mealtime insulins in insulinopenic diabetes, indicates a waning of effect with once-daily dosing (7). Another limitation of existing basal insulin analogues is that they are not available as combination formulations with fastacting insulin analogues.

The achievement of a truly stable 24-hour basal blood glucose-lowering effect will require the development of an insulin that achieves steady state pharmacokinetics with a low peak:trough ratio, and for this to be achieved with a dosing frequency that does not exceed once daily, the total duration of action will need to comfortably exceed 24 h. Furthermore, a truly stable basal blood glucose-lowering profile will require the insulin to have low variability of action from injection to injection, and this goal is likely to be compromised by precipitation and subsequent redissolution.

To develop a basal insulin fulfilling these criteria, a novel mechanism of protraction is needed. Because subcutaneous absorption rate correlates closely with molecular size, insulins capable of forming higher molecular weight multihexameric complexes that remain soluble could provide a new approach to protracting subcutaneous absorption. This in turn, however, would require attaching ligands to the insulin molecule that were capable of linking hexamers to each other, and for this process to succeed an understanding of hexameric conformation is critical. The insulin hexamer can exist in different conformational states according to whether residues $1-6$ of the B-chains (F-L, Fig. 1) of the constituent monomers are in a tense $(\mathrm{T})$ or relaxed $(\mathrm{R})$ conformation $(8,9)$. This process is driven by binding of phenol and anion (chloride) ligands and spectroscopy studies have suggested three possible conformations for the insulin hexamer: $\mathrm{R}_{6}$ in which both poles of the hexamer are closed, $\mathrm{R}_{3} \mathrm{~T}_{3}$ in which one pole is closed and the other open, and $\mathrm{T}_{6}$ in which both poles are open (Fig. 2). The significance of this is that the nature of any interactions occurring between the hexamers of an insulin analogue that involve contact between the artificial ligand moieties and potential binding sites on other hexamers are likely to differ depending on conformational state, i.e. whether the amino acid residues and/or zinc ions situated in the hexamer cores are exposed ( $\mathrm{T}$ conformation) or shielded ( $\mathrm{R}$ conformation).

A previous study involving acylation of insulin with cholic acid ligands via a glutamic acid spacer indicated that high molecular weight insulin complexes could be formed and the duration of action of the insulin significantly increased (10). It was therefore speculated that acylation of insulin in this way with a tailored side-chain could provide a molecular approach to engineer insulin analogues that would form multihexamers with ultra-long durations of action. The present paper reports a series of investigative studies designed to determine the relevant physico-chemical properties of a series of insulin analogues thought potentially capable of hexamerhexamer interaction and multihexamer formation. The ultimate goal was to identify candidate molecules with potential for clinical development. To this end, several acylated insulin analogues were constructed and studied in a series of in vitro experiments, involving circular dichroism spectroscopy (CDS), size exclusion chromatography (SEG) and multiangle light scattering (MALS). These studies were designed to characterise the molecular self-association states and hexameric conformation (with reference to human insulin and

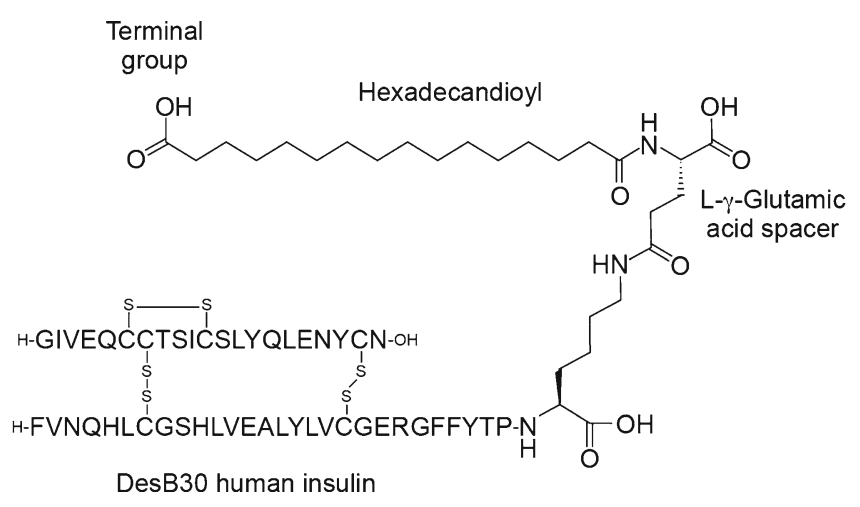

Fig. I Schematic representation of insulin degludec. DesB30 human insulin was acylated at the $\varepsilon$-amino group of Lys ${ }^{\text {B29 }}$ with hexadecandioic acid via a $\mathrm{Y}$-L-glutamic acid linker. The structural elements of the ligand were examined for their impact on the ability of the resulting insulin analogue to form multihexamers (Table I). 
Fig. 2 Schematic representation of insulin-zinc hexamer conformation. In a typical pharmaceutical formulation insulin adopts the relaxed $(R)$ conformation. Upon depletion of phenol after injection the poles will subsequently (one pole at a time) adopt the tense (T) conformation, exposing the core and zinc ions. Ultimately zinc dissociates and the hexamer disassembles into dimers and insulin monomers.
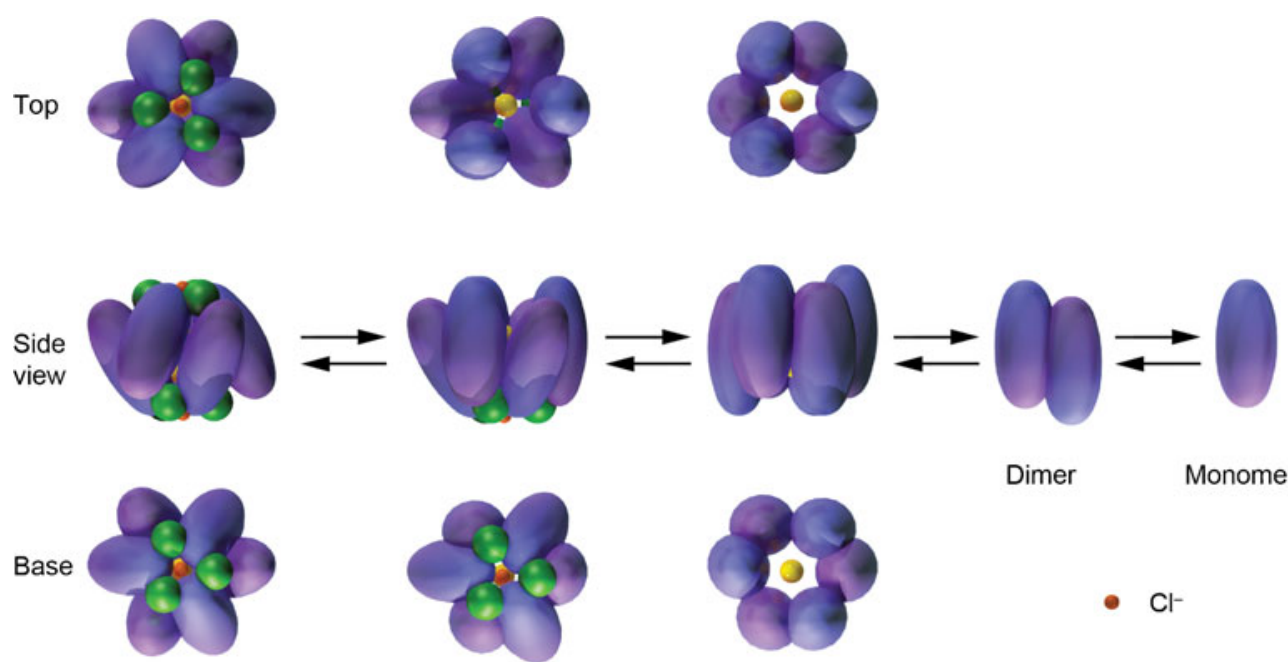

Dimer
Monomer
Degludec

hexamer

( $R_{6}$-state)

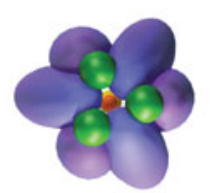

Degludec hexamer ( $T_{3} R_{3}$-state)

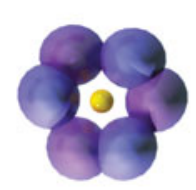

Degludec

hexamer

( $\mathrm{T}_{6}$-state)

$\mathrm{Zn}^{2+}$

Phenol

comparator analogues) in environments (of varying phenol and zinc content) designed to simulate the pharmaceutical formulation and subcutaneous injection depot.

\section{MATERIALS AND METHODS}

\section{Preparations, Formulation, and Labelling of Insulin Analogues}

Insulin analogues were prepared by acylations (with fatty-acid based ligands) of the $\varepsilon$-amino group of Lys ${ }^{\mathrm{B} 29}$ of biosynthetic desB30 human insulin. The ligands were composed of fatty acids or fatty diacids carrying a glutamic acid spacer molecule and attached to Lys ${ }^{\text {B29 }}$ by an amide bond (Fig. 1). The ligands were coupled by peptide bonds as described previously (11). Formulations for SEC-analysis and SEC-MALS were prepared by suspension of the appropriate insulin analogues, which were dissolved by addition of dilute sodium hydroxide before addition of the pharmaceutical excipients in the following order: glycerol $1.7 \%$, $16 \mathrm{mM}$ m-cresol, $16 \mathrm{mM}$ phenol and zinc acetate to a final concentration of two or six zinc ions per six insulin monomers. The $\mathrm{pH}$ value was then adjusted to 7.4. In addition, formulated samples of insulin analogues for human serum albumin binding assays were labelled by ${ }^{125} \mathrm{I}_{2}$ iodination of $\mathrm{T}_{\mathrm{yr}}{ }^{\mathrm{Al}}$ (12).

\section{Circular Dichroism Spectroscopy Studies}

CDS was used to assess the conformation of insulin hexamers (including changes following loss of pharmaceutical preservatives), as well as the relative propensity of monomers to remain self-assembled as dimers. Insulin-zinc hexamers are ordinarily organised in a $\mathrm{T}_{6}$ confirmation, but with the addition of chloride and phenol (as in a pharmaceutical formulation) this conformation can change to $\mathrm{T}_{3} \mathrm{R}_{3}$ and $\mathrm{R}_{6}$ states (13). The phenol concentration of the medium was therefore varied to assess whether conformational changes take place between conditions designed to simulate those encountered in the cartridge of a clinical formulation, and those in the subcutaneous environment following injection, where phenol is expected to diffuse away from the depot (4). Conformational changes were followed using $251 \mathrm{~nm}$ CDS-intensity as previously described (13). Samples of 0.6 mM insulin, $10 \mathrm{mM}$ Trisperchlorat buffer, $\mathrm{pH}$ 8.0, $0.6 \mathrm{mM}$ zinc acetate and phenol concentrations varying from $0-30 \mathrm{mM}$ were prepared. Phenol was added to the insulin solution before zinc acetate. The disassembly of insulin into monomers was assessed by probing the tyrosine chromophores at $276 \mathrm{~nm}$ as previously described (14). For this purpose, samples of insulin analogues were prepared in appropriate concentrations ranging from 5$2000 \mu \mathrm{M}$ in $10 \mathrm{mM}$ Tris-perchlorat buffer, $\mathrm{pH}$ 7.4. CDS monitoring of this dilution series was used to identify the concentration at which the monomeric state was reached.

\section{Size-Exclusion Chromatography Studies}

SEG experiments monitored by UV-absorbance were performed to characterise the molecular size of self-assembled units of the candidate insulins and references, specifically to evaluate their ability to form insulin dihexamers and multihexamers in the presence of zinc ions. Again, phenol concentrations were varied to simulate conditions before and following subcutaneous injection, and zinc concentrations were varied to determine the role of zinc in enabling the formation of complexes. Acylated analogues and human 
insulin were compared in this model to determine whether any observed properties would be common to all analogues featuring a diacid and/or spacer and/or whether the acylated fatty acid chain length was relevant in determining selfassociation profile.

Samples of human insulin, or insulin analogue, in a formulation containing from zero to six zinc ions per six insulin monomers and $16 \mathrm{mM}$ phenol and $16 \mathrm{mM}$ m-cresol (to simulate conditions following subcutaneous injection), were subjected to SEC at $37^{\circ} \mathrm{C}$ using a Superose $6 \mathrm{PC}(0.32 \times 30)$ $\mathrm{cm}$ and Superose $6 \mathrm{HR}(1 \times 30) \mathrm{cm}$ (separation range $5 \times 10^{3}-$ $5 \times 10^{6} \mathrm{D}$ determined for spherical proteins, GE Lifesciences, USA). The Superose 6 PC column was eluted $50 \mu \mathrm{L} / \mathrm{min}$ and the Superose $6 \mathrm{HR}$ column was eluted with a flow of $250 \mu \mathrm{L} /$ min employing phenol-free buffer comprising NaCl 140 mM, $\mathrm{NaN}_{3} 1.54 \mathrm{mM}$ and Tris-HCl $10 \mathrm{mM}$, pH 7.4 (4). The effluent was monitored at $276 \mathrm{~nm}$, and injection volume was $20 \mu \mathrm{L}$ and $200 \mu \mathrm{L}$ respectively. The apparent molecular masses of the chromatographic peaks were estimated from a standard curve (15) employing as references: Blue Dextran, Thyroglobulin, Ferritin, HSA, Co(III)insulin hexamer (16) and X2 (monomeric AspB9, GluB27 human insulin) (3).

The analysis was repeated with phenol added to the elution buffer to a final concentration of $2 \mathrm{mM}$ employing a related column $($ Superose $12 \AA(1 \times 30) \mathrm{cm}$ GL separation range $1 \times 10^{3}-3 \times 10^{5} \mathrm{D}$ determined for spherical proteins, GE Healthcare, USA) to simulate the composition of a pharmaceutical insulin formulation (10).

\section{Light-Scattering Studies}

SEC-MALS analysis was carried out employing a high performance liquid chromatography (HPLG) system connected to a DAWN ${ }^{\circledR}$ HELEOSTM MALS detector followed by a WyattQELSTM dynamic light scattering detector (DLS), and an Optilab ${ }^{\circledR}$ rEX $^{\text {TM }}$ refractive Index (RI) detector. ASTRA ${ }^{\circledR}$ $\mathrm{V}$ software was used to analyse data. The detectors and software were obtained from Wyatt Technology Inc., Santa Barbara, CA, USA. For proteins, a typical refractive index increment value $(d n / d c)$ of 0.185 is used (17-19).

\section{Albumin-Binding Studies}

Since albumin binding at the depot and in the circulation contributes to the prolonged kinetics of insulin detemir (4), the albumin-binding affinities of the study analogues were also measured and assessed in proportion to that of insulin detemir. Binding to HSA was determined as previously described (20). Human fatty-acid-free serum albumin was immobilised to divinylsulfone-activated Sepharose 6B MiniLeak (Kem-En-Tec, Copenhagen, Denmark), to a concentration of $0.2 \mathrm{mM}$ suction dried gel. The immobilised HSA was suspended and diluted to cover the range $0-10 \mu \mathrm{M}$ in
100 mM Tris-HCl, pH 7.4, containing $0.025 \%$ Triton X100 to prevent non-specific adhesion. After incubation for $2 \mathrm{~h}$ at $23{ }^{\circ} \mathrm{C}$, free and albumin-bound analogue were separated by centrifugation. Plots of bound/free analogue vs. albumin concentration were linear and the association constant $\mathrm{Ka}$ was estimated from the slope of the plot:

$\kappa a=\frac{B}{F} \frac{1}{[\text { HSAimm }]}$

\section{RESULTS}

\section{Size-Exclusion Chromatography Studies}

SEC data showing the ability of zinc hexamers of insulin analogues to self assemble are presented in Table I. SEC analysis of formulations containing six zinc ions per six insulin molecules in phenol-free buffer showed that the presence of a lengthy ( $\geq 16$ carbon atoms) diacid plus glutamic acid spacer bestowed the analogue with an ability to form large multihexamer complexes (Table I). Thus, insulin acylated by hexadecandioyl- $\gamma$-L-Glu (insulin degludec) and octadecandioyl- $\boldsymbol{\gamma}$-L-Glu formed multihexamers with an apparent molecular weight $(\mathrm{MW})>5 \mathrm{MDa}$.

Changing the terminal carboxylic acid of the insulin ligand to 16 -hydroxyhexadecanoyl- $\gamma$-L-Glu- or hexadecanoyl- $\gamma$-LGlu desB30 human insulin disrupted the ability to form multihexamers. The more hydrophobic hexadecanoyl- $\boldsymbol{\gamma}$-L-Glu desB30 human insulin was also unable to form multihexamers. Furthermore, changing attachment of the glutamic acid spacer molecule to hexadecandioyl- $\alpha$-L-Glu, or substitution of the spacer molecule by its D-form (hexadecandioyl $-\boldsymbol{\gamma}$ D-Glu), also disrupted mutihexamer formation (Table I).

When SEC was repeated using the same formulations, but with zinc content reduced to two zinc ions per six insulin molecules, the analogues displayed similar ranking in terms of the relative molecular masses of the largest elution peaks obtained, but with weaker self-association and hence elution of smaller-mass complexes. So for example, when formulated with six zinc ions per six insulin molecules, human insulin eluted with the largest peak corresponding to a mean $22 \mathrm{kDa}$ and insulin degludec with a peak corresponding to complexes with molecular masses up to at least $5 \mathrm{MDa}$, but the insulins eluted with main peaks of lower molecular weights $(371 \mathrm{kDa}$ for insulin degludec and $21 \mathrm{kDa}$ for human insulin) when formulated with two zinc ions per six insulin molecules (Table I).

When the SEC-analysis was repeated with addition of phenol to the elution buffer (simulating the injected formulation), the insulins eluted with a range of values from 81 down to $57 \mathrm{kDa}$ (Table I). The higher values are consistent 
Table I Physicochemical and Pharmacological Characteristics of Study Insulins

\begin{tabular}{|c|c|c|c|c|c|c|}
\hline \multirow[b]{2}{*}{ Analogue $^{a}$} & \multirow[b]{2}{*}{$\begin{array}{l}\text { Conformational } \\
\text { state in } \\
\text { formulation with } \\
\text { zinc and phenol }\end{array}$} & \multirow[b]{2}{*}{$\begin{array}{l}\text { Relative } \\
\text { HSA } \\
\text { affinity } \\
\text { (vs. } \\
\text { detemir) }\end{array}$} & \multicolumn{4}{|c|}{$\begin{array}{l}\text { Apparent molecular mass }(\mathrm{kDa}) \\
\text { Mean value of largest elution peak }\end{array}$} \\
\hline & & & $\begin{array}{l}6 \mathrm{Zn} / 6 \\
\text { insulin }\end{array}$ & $\begin{array}{l}2 \mathrm{Zn} / 6 \\
\text { insulin }^{\mathrm{d}}\end{array}$ & $\begin{array}{l}6 \mathrm{Zn} / 6 \\
\text { insulin } \\
+ \text { phenol }\end{array}$ & $\begin{array}{l}2 \mathrm{Zn} / 6 \\
\text { insulin }^{\mathrm{e}} \\
+ \text { phenol }\end{array}$ \\
\hline Dodecandioyl-y-L-Glu & $T_{3} R_{3}$ & 0.05 & 120 & 76 & 81 & 57 \\
\hline Tetradecandioyl-y-L-Glu & n.d. & 0.1 & 391 & 24 & 75 & 71 \\
\hline $\begin{array}{l}\text { Insulin degludec: } \\
\text { Hexadecandioyl-y-L-Glu }\end{array}$ & $T_{3} R_{3}$ & 2.4 & $>5000$ & 371 & 74 & 69 \\
\hline Octadecandioyl-y-L-Glu & $T_{3} R_{3}$ & 8.7 & $>5000$ & 1.364 & 77 & 69 \\
\hline Hexadecanoyl-y-L-Glu & $\mathrm{T}_{3} \mathrm{R}_{3}$ & 3.5 & 56 & 56 & 70 & 65 \\
\hline I6-hydroxyhexadecanoyl-y-L-Glu & $T_{3} R_{3}$ & 0.8 & 104 & 58 & 70 & 66 \\
\hline Hexadecandioyl-y-D-Glu & $\mathrm{T}_{3} \mathrm{R}_{3}$ & 4.9 & 422 & 186 & 76 & 67 \\
\hline Hexadecandioyl-a-L-Glu & $T_{3} R_{3}$ & 2.4 & 217 & 79 & 76 & 66 \\
\hline Insulin detemir tetradecanoyl & $R_{6}$ & 1.00 & 57 & 30 & 44 & 31 \\
\hline Human insulin & $\mathrm{R}_{6}$ & - & 22 & 21 & 29 & 26 \\
\hline
\end{tabular}

HSA Human serum albumin

${ }^{a}$ Acylated $\mathrm{N}^{\varepsilon B 29}$ - desB30 human insulin

b Samples of $0.6 \mathrm{mM}$ insulin, $10 \mathrm{mM}$ Tris-perchlorat buffer, $\mathrm{pH}$ 8.0, $0.6 \mathrm{mM}$ zinc acetate and phenol concentrations varying from 0-30 mM were prepared. Phenol was added to the insulin solution before zinc acetate

${ }^{\mathrm{C}}$ The association constant $\mathrm{K}_{\mathrm{a}}$ for binding of HSA to $\mathrm{Lys}^{\mathrm{B} 29}\left(\mathrm{~N}^{\varepsilon}\right.$-tetradecanoyl) des-(B30) human insulin (insulin detemir) is $2.4 \times 10^{5} \mathrm{I} / \mathrm{mol}$ at room temperature. Analogue association constants are presented relative to detemir, all values are means of double determination

${ }^{\mathrm{d}}$ The maximum molecular mass observed after SEC-analysis of $200 \mu \mathrm{l}$ of $0.6 \mathrm{mM}$ insulin analogue formulated in $1.7 \%$ glycerol, $16 \mathrm{mM}$ phenol, $16 \mathrm{mM} \mathrm{m}$-cresol and six and two zinc ions per hexamer at $37^{\circ} \mathrm{C}$. The column was eluted by $140 \mathrm{mM} \mathrm{NaCl}, 1.54 \mathrm{mM} \mathrm{NaN}$ and I $0 \mathrm{mM}$ Tris- $\mathrm{HCl}$, pH 7.4, at a flow of $0.25 \mathrm{ml} / \mathrm{min}$ e SEC-analysis as ${ }^{d}$ but with addition of phenol corresponding to $2 \mathrm{mM}$ to the elution buffer

with a dihexameric state (e.g. insulin degludec). For comparison, human insulin eluted with a molecular weight $(29 \mathrm{kDa})$ close to that of an insulin hexamer in the presence of phenol and six zinc per six insulin molecules.

The correlation between zinc concentration and multihexamer formation of insulin degludec was studied in a dose-response experiment where formulations ranging from zero to six zinc ions per six insulin degludec were subjected to SEC. The fraction of insulin degludec eluted as multihexamers changed from $0 \%$ to almost $100 \%$ across this increasing range of zinc concentrations, while the converse was observed for monomers (Fig. 3), demonstrating that as zinc is depleted the multihexamers likely shorten by disassembly of individual hexamers into monomers. Repetition of this experiment returned almost identical results (Fig. 3b).

\section{Light-Scattering Studies}

Data concerning the molar mass distribution of the peaks for insulin degludec and octadecandioyl- $\gamma$-L-Glu desB30 human insulin analysed by SEC MALS are shown in Fig. 3. In the presence of two zinc ions per six insulin molecules, both analogues show a peak at $78 \mathrm{~min}$, which corresponds to a monomer-dimer equilibrium, and a peak at around 38 min corresponding to a multihexamer. For degludec, the maximum height of the multihexamer peak occurred at $2 \mathrm{MDa}$ in this analysis. In the presence of six zinc ions per six insulin molecules, $>95 \%$ of the two analogues eluted at about 32 min (Fig. 3). For degludec the average molar mass of this broad peak is $2.9 \mathrm{MDa}$ ranging from $700 \mathrm{kDa}$ to $5 \mathrm{MDa}$. The corresponding peak for octadecandioyl- $\gamma$-LGlu desB30 human insulin was a little less broad indicating a more homogenous size of the multihexamers.

The radius of gyration $\left(\mathrm{R}_{\mathrm{g}}\right)$ and hydrodynamic radius $\left(\mathrm{R}_{\mathrm{h}}\right)$ of the high molecular weight fraction of the two zinc formulations (Fig. 3) were determined by MALS and DLS, respectively. In the case of insulin degludec, the respective values obtained for $R_{g}$ and $R_{h}$ were 58 and $21 \mathrm{~nm}$, with respective values for octadecandioyl- $\gamma$-L-Glu desB30 human of 40 and $16 \mathrm{~nm}$. Hence the $\rho$ parameter, $\rho=R_{g} / R_{h}$, were 2.8 and 2.5, respectively, for insulin degludec and octadecandioyl- $\gamma$-L-Glu desB30 human insulin. This value indicates long stiff filaments (21). A conformation plot, i.e. $\log \left(\mathbf{R}_{\mathrm{g}}\right)$ plotted vs. $\log \left(\mathbf{M}_{\mathrm{w}}\right)$, results in a slope of $\sim 0.8$ for both insulin analogues (data not shown) also supporting a stiff and elongated conformation. 
a
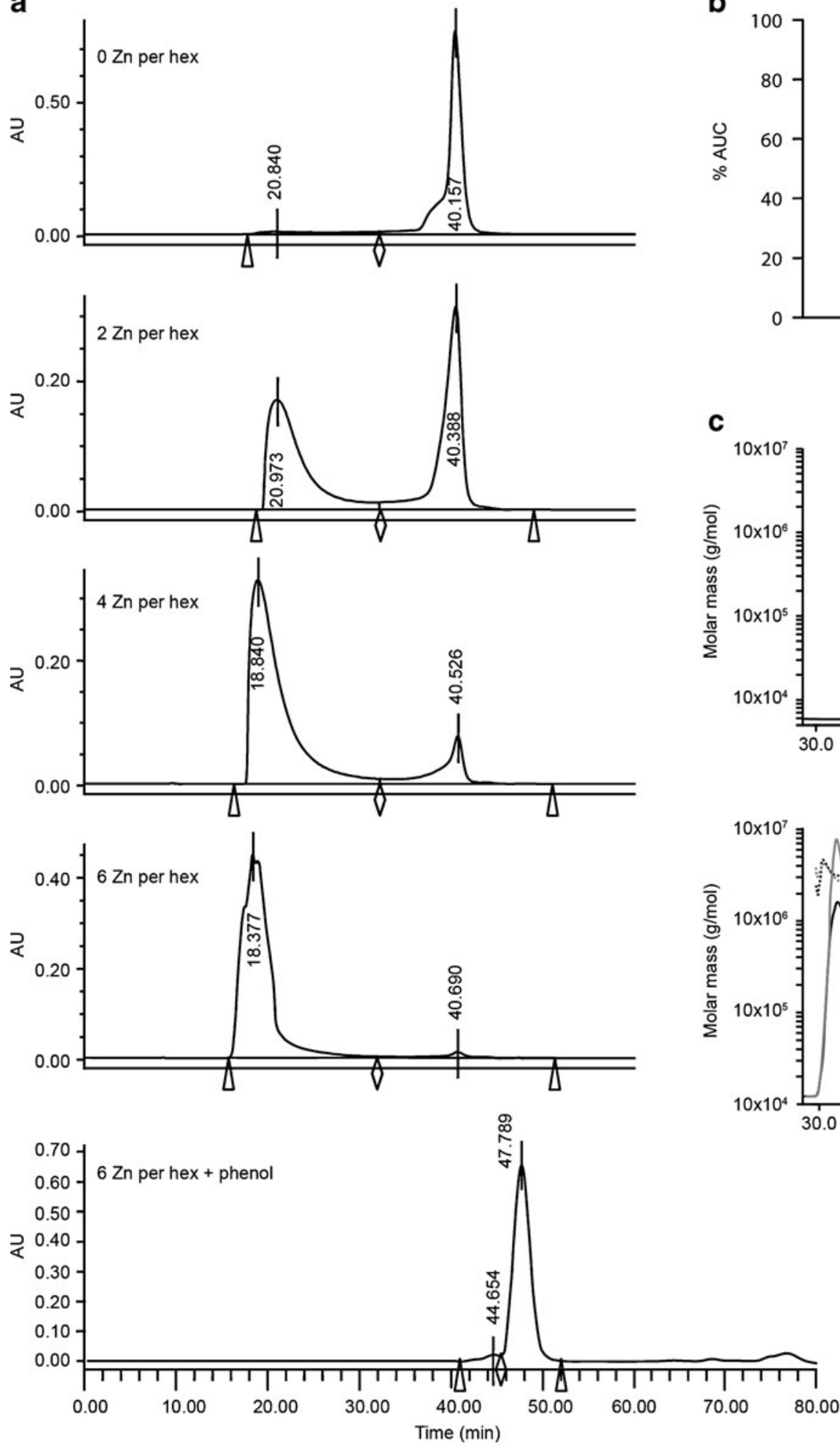

b

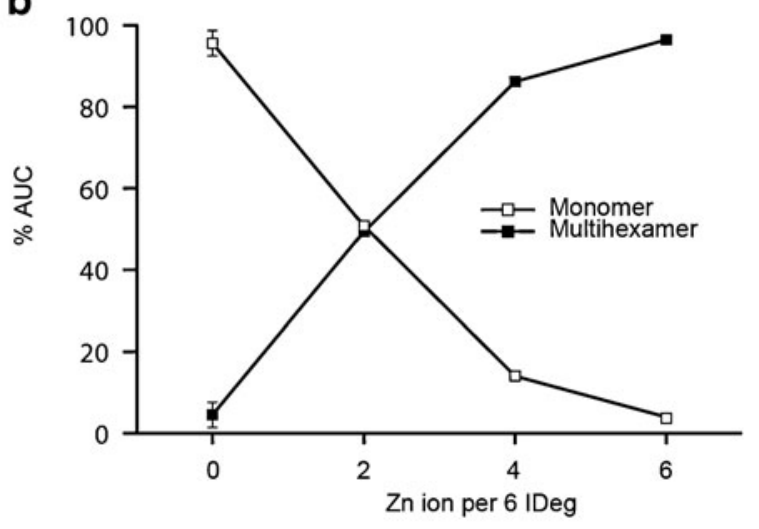

C
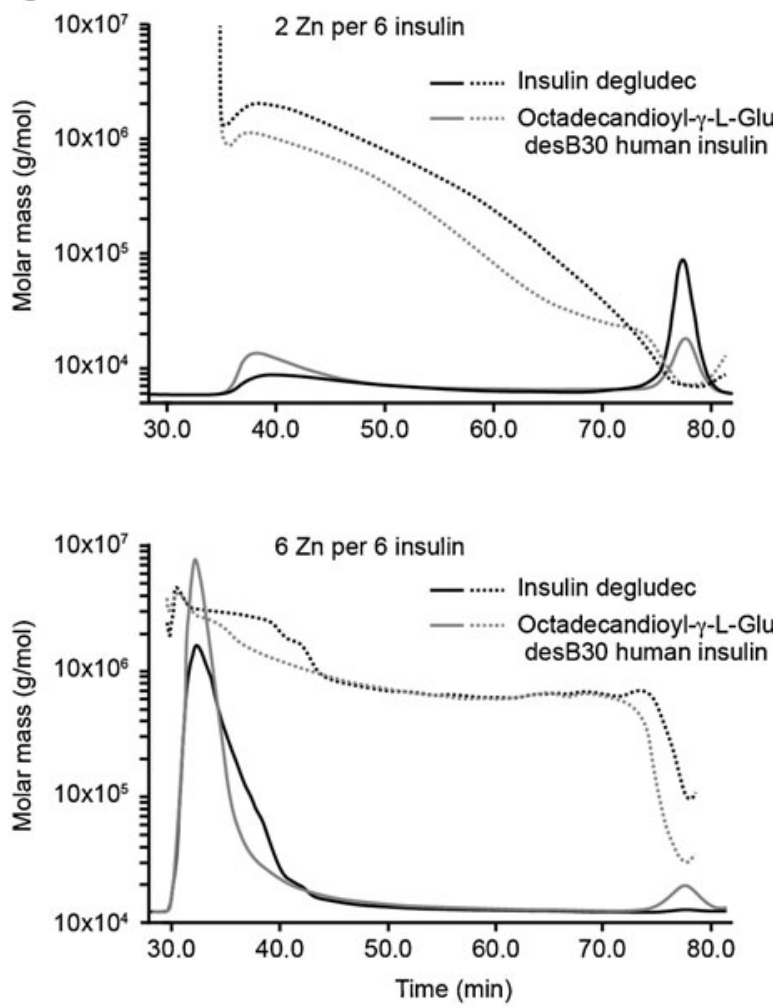

\section{Circular Dichroism Spectroscopy Studies}

CDS analysis of the insulin zinc hexamer formulations showed that in the presence of phenol, the analogues carrying a ligand composed of a fatty acid and glutamic acid spacer molecule displayed $\mathrm{T}_{3} \mathrm{R}_{3}$ conformation (Table I). With removal of phenol, this changes to $\mathrm{T}_{6}$ conformation. There were some differences between the 
4 Fig. 3 Size exclusion chromatography (SEC) evidence of various insulin degludec self-association states. Insulin degludec was analysed by SEC in the absence of phenol employing a Sepharose 6Pc column after formulation with an increasing number of zinc ions per six insulin degludec molecules (a). The proportion eluting as multihexamers was closely related to the zinc content. (b) Reciprocal change in the monomer and multihexamer content going from phenol-containing formulations ranging from zero to six zinc ions per six insulin degludec molecules. The traces show the mean and minimum and maximum values (as bars) from duplicate analyses. Near identical values were obtained in each analysis. The lowermost trace in panel A shows SEC of an insulin degludec formulation in the presence of phenol employing a Sepharose I2GL column. Insulin degludec elutes with a peak corresponding to an insulin dihexamer. The small peak that elutes at approximately 44 min corresponds to a molecular weight of I $8 \mathrm{kDa}$. The peak at approximately 78 min does not contain protein. (c) shows the molar mass distributions of insulin degludec and octadecandioyl-y-L-Glu desB30 human insulin at two different zinc concentrations in the presence of phenol determined by SEC-MALS. Solid lines in the chromatograms represent traces from the RI detector, dotted lines show the molar mass distribution. The buffer used is without phenol and contains $10 \mathrm{mM}$ Tris- $\mathrm{HCl}, \mathrm{pH} 7.4,140 \mathrm{mM}$ $\mathrm{NaCl}$.

insulins tested in their conformational responses to increasing phenol concentrations from 0 to $30 \mathrm{mM}$, with most eventually taking on $\mathrm{R}_{6}$ conformation. Thus, for example, the response from human insulin changed from -1.5 to $-6.5 \Delta \varepsilon\left(\mathrm{l} \mathrm{mol}^{-1} \mathrm{~cm}^{-1}\right)$ at $251 \mathrm{~nm}$ (Fig. 4) reflecting a change in conformational state from $T_{6}$ through $T_{3} R_{3}$ to $\mathrm{R}_{6}$. In contrast, insulin degludec only obtained $\mathrm{T}_{3} \mathrm{R}_{3}$ in the presence of phenol. However insulin degludec did obtain the $\mathrm{R}_{6}$ conformation in the presence of $100 \mathrm{mM}$ imidazol and $30 \mathrm{mM}$ resorcinol at $\mathrm{pH}$ 7.4.

CDS analysis of the zinc-free formulations of the tested insulins revealed a large variation in their tendency to

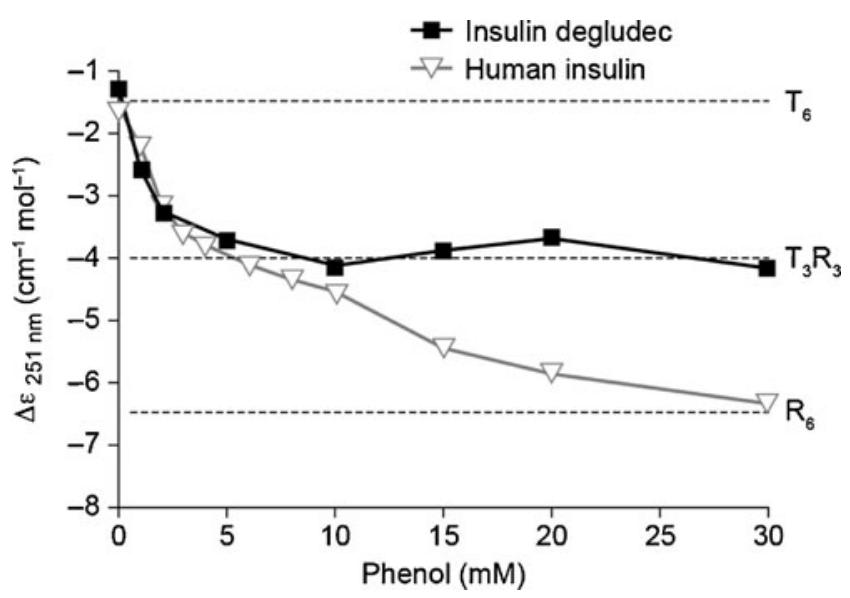

Fig. 4 Circular dichroism spectroscopy (CDS) assessment at $25 \mathrm{I} \mathrm{nm} \mathrm{of}$ the allosteric interconversion of insulin degludec and human insulin with increasing phenol concentration. The insulin concentration was $0.6 \mathrm{mM}$ containing six $\mathrm{Zn}^{2+}$ per six insulin degludec and two $\mathrm{Zn}^{2+}$ per six insulin in Tris-perchlorate $10 \mathrm{mM}, \mathrm{pH}$ 8.0. Degludec obtains $T_{3} R_{3}$ conformation at $10 \mathrm{mM}$ phenol but remains unchanged thereafter. Human insulin obtains $\mathrm{R}_{6}$ conformation at $30 \mathrm{mM}$ phenol. dissociate into insulin monomers. All test insulins remained as monomers at a concentration up to $1 \mathrm{mM}$, whereas Lys ${ }^{\mathrm{B} 29} \mathrm{~N}^{\varepsilon}$-hexadecanoyl- $\boldsymbol{\gamma}$-L-Glu desB30 human insulin (the fatty mono acid derivative) was monomeric up to $40 \mu \mathrm{M}$. Human insulin was monomeric to a concentration of $0.005 \mu \mathrm{M}$ ) and insulin detemir up to $19 \mu \mathrm{M}(14)$.

\section{DISCUSSION}

The GDS and SEC data show the molecular conformation and self-association states of the study analogues before and after injection. As elaborated below, the properties of insulin degludec emerged in these studies as particularly appealing for further clinical development.

Firstly, the SEC analysis reveals the extent to which the insulin analogues were self-associated in environments simulating the pharmaceutical formulation and the subcutaneous environment. In a pharmaceutical formulation containing phenol and cresol, and when using a phenol-containing elution buffer to avoid dissociation of phenol from the insulin complex, all the formulated insulin analogues eluted primarily as a single species with a molecular weight corresponding to the size of an insulin dihexamer (Table I). All the studied analogues displayed this property apart from insulin detemir, showing that the glutamic acid linker must be present for dihexamers to form. Removal of phenol from the elution buffer during SEC resembles the dilution of phenol after subcutaneous injection because phenol is a small molecule that diffuses readily in the tissue and across membranes, in contrast to the insulin zinc complex. The removal of phenol during SEC was associated with an increase in the apparent molecular mass at which some of the analogues eluted. This effect was particularly marked for insulin degludec and octadecandioyl- $\gamma$-L-Glu desB30 human insulin, both of which displayed multihexamer formation with an apparent MW $>5 \mathrm{MDa}$ (Table I). Multihexamer formation was impaired, however, in analogues featuring minor changes of the glutamic spacer molecule compared to degludec. Furthermore, the terminal carboxylic acid appeared to be critical for multihexamer formation since substitution with a hydroxymethyl group (16-hydroxyhexadecandioyl- $\gamma$-L-Glu) or a methyl group (hexadecanoyl- $\gamma$-L-Glu) significantly reduced multihexamer formation. In addition, multihexamer formation was inhibited by changing attachment of the glutamic acid spacer molecule to hexadecandioyl- $\alpha$-L-Glu, or substituting the spacer molecule with its D-form (hexadecandioyl- $\gamma$-D-Glu). It therefore appears that multihexamer formation is dependent on the presence of a diacid of at least 16 carbon atoms connected to $\mathrm{Lys}^{\mathrm{B} 29}$ of insulin via a $\gamma$-L-glutamic acid spacer molecule.

When the zinc content was reduced in the insulin formulation applied to the SEC column and elution was conducted 
with phenol-free buffer, insulin degludec eluted with a smaller apparent molecular mass indicating that the multihexamer complex is dependent on the zinc concentration. This was confirmed in the zinc dose-response SEC analysis, where, in the absence of zinc, insulin degludec eluted almost exclusively as a monomer.

Octadecandioyl- $\boldsymbol{\gamma}$-L-Glu desB30 human insulin also eluted at smaller sizes when applied in a formulation with only two zinc per six insulin molecules, but the apparent molecular mass of the largest elution peak was still in excess of 1.3 MDa, showing that the multihexamer chains of this analogue are much slower to disassemble, hence the absorption kinetics of this analogue may to be too long to be clinically applicable.

When light scattering was used to monitor SEC employing the six zinc formulation, an almost quantitative formation of multihexamers was obtained but insulin degludec displayed a broader MW distribution of higher MW than octadecandioyl- $\boldsymbol{\gamma}$-L-Glu desB30 human insulin. These differences might be caused by differences in the kinetics of formation of the two multihexamers.

The CDS analysis showed that analogues acylated by ligands composed of a spacer molecule and a fatty acid readily adopt the $T_{3} R_{3}$ hexamer conformation in a pharmaceutical formulation, with the SEC data suggesting that this species will assemble into dihexamers. Human insulin and insulin detemir also adopt the $\mathrm{T}_{3} \mathrm{R}_{3}$ conformation, but in contrast they eventually adopt $\mathrm{R}_{6}$ conformation at increasing concentrations of phenol (Fig. 4; 14). In the case of insulin degludec, the $T_{3} R_{3}$ dihexamer appears to be highly stable since in further experiments (analytical ultra centrifugation and CDS, data not shown) this analogue could only be made to obtain $\mathrm{R}_{6}$ conformation as an insulin-zinc hexamer when formulated at neutral $\mathrm{pH}$ together with resorcinol and imidazol, which bind more tightly to the insulin's 'phenol binding pockets' and are stronger inducers of the $\mathrm{R}$ state than phenol (22).

The CDS and SEC observations suggest that $T_{3} R_{3}$ dihexamers are held together by the binding of two insulin hexamer $\mathrm{T}_{3}$ surfaces, and it can be speculated that this is the result of a single fatty acid contact between these surfaces. In the case of insulin degludec and octadecandioyl- $\gamma$-L-Glu desB30 human insulin, the change in conformation to $\mathrm{T}_{6}$ enables side chain contacts to be made at each $\mathrm{T}_{3}$ pole of a hexamer so that the large molecular mass species eluted in phenol-free SEG likely represent soluble hexamer chains, with each chain potentially linking hundreds of hexamer units.

The exact nature of the interaction between hexamers in the $\mathrm{T}_{3} \mathrm{R}_{3}$ dihexamer and the $\mathrm{T}_{6}$ multihexamer is not known. However, a mechanism that would be plausible and compatible with the experimental results would involve coordination of the terminal carboxylic acid residue of the fatty di-acid chain to a zinc atom in the neighbouring hexamer. In the multihexamer state, hexamers would therefore be joined together in a structure that could be likened, speculatively, to 'pearls on a string', with the fatty acid chains analogous to the 'string' and the zinc ions within the hexamers being the 'pearls'. For the $\mathrm{T}_{3} \mathrm{R}_{3}$ hexamer, this mechanism would only allow formation of di-hexamers because the $T_{3} R_{3}$ hexamer is only open at one pole hence a fatty acid coordination would only be feasible by the two hexamers coming together via their open poles. When the conformation changes to $\mathrm{T}_{6}$ following dissociation of phenol, the hexamer opens at both poles, and the fatty di-acid could access zinc atoms in neighbouring hexamers to both sides, allowing formation of multihexamer chains. This hypothesis is supported by the light scattering data showing that $\rho=2.8\left(\rho=R_{g} / R_{h}\right)$ for insulin degludec; this value is in good agreement with values obtained for elongated and relatively stiff molecules (21).

This putative mechanism explains the zinc-dependency of multihexamer formation, and can also explain why the fatty acid side chains need to be of a sufficient length and stereochemical orientation (favouring L-Glu over D-Glu and gamma-Glu over alpha-Glu for the linker), because a certain three dimensional orientation would likely be needed for the fatty acid side chain to contact the neighbouring zinc. Finally, this mechanism would explain why a dicarboxylic acid can induce multihexamer formation, whereas a mono-carboxylic acid cannot, since the terminal carboxylic acid would be needed for the fatty acid to act as a ligand with a zinc ion in the insulin hexamer.

Importantly, although ligand-mediated multihexamer formation leads to high molecular weight insulin analoguezinc complexes, all the studied insulin analogues displayed full solubility as zinc phenol formulations and as multihexamers in physiological saline. The soluble state of the insulin multihexamer is of particular interest from the point of view of developing formulations for clinical use, since previous studies have highlighted the advantages of a soluble depot over a depot composed of precipitate particles with respect to reproducible absorption kinetics after subcutaneous injection $(5,23)$.

It is important to note that the formation of complicated structures like the insulin degludec multihexamer is likely to be sensitive to the environment during the time of formation. Thus, a previous study employing analytical ultra centrifugation reported a molecular weight of 44MDa (24). The present investigation can only suggest that the multihexamers are large structures, likely comprising several hundred hexamer units. The exact size of multihexamer chains formed in vivo at the site of subcutaneous injection remains elusive. In future studies, further analysis of larger aggregates using other types of methodologies should be performed (25). Large-sized protein-like structures could 
potentially evoke immunological responses, and this issue is relevant, for example, for antibody-based therapeutics for which neutralising antibodies can impact efficacy over time (26). Aggregates of endogenous proteins, particularly when denatured, may also induce an immunological response (27). Therefore, the phase 3 clinical studies of insulin degludec, in which have been included close to 10,000 patients, have collected data on antibody formation and injection site reactions. Available data are reassuring, showing that, for all participants, the level of insulin degludec-specific antibodies was close to, or below, the limit of detection at screening and remained at the same level after 16 weeks of treatment $(28,29)$. Furthermore, dermatological injection site reactions occurred only rarely in these studies with no evidence of an increased incidence vs. insulin glargine.

The CDS analyses in zinc-free formulations show that the test analogues, including insulin degludec, are monomers at concentrations higher than $1 \mathrm{mM}$, which means that once multihexamers dissociate due to zinc diffusion, the liberated dimers will immediately dissociate into monomers. This is likely to be the state in which insulin degludec is absorbed into the circulation, since monomers of insulin pass faster through the tissue and across membranes than higher molecular weight complexes.

A potentially important consequence of the property of forming very stable $T_{3} R_{3}$ dihexamers in a pharmaceutical formulation (and multihexamers at the site of injection) is that other insulins (e.g. rapid-acting insulins) can be coformulated without the risk of inter-exchange of monomers to form hybrid hexamers either in the cartridge or injection depot. This could enable the development of combination products with discrete preservation of the PK profiles of the component insulins. Indeed, a co-formulation of insulin degludec plus insulin aspart is currently undergoing clinical investigation (30).

In summary, insulin degludec and octadecandioyl- $\gamma$-LGlu desB30 human insulin stood out in our analyses as compounds able to form multihexamer chains following subcutaneous injection, and insulin degludec further stood out as suitable for clinical development due to a favourable $\mathrm{PK} / \mathrm{PD}$ profile with a plasma $\mathrm{t}^{1 / 2}$ of $25 \mathrm{~h}$ in humans in subsequent studies. It can be concluded that insulin degludec has a unique mechanism of protraction; in the presence of phenol and zinc, (as in a pharmaceutical formulation) it forms a soluble and stable dihexamer, but after injection, as phenol diffuses away, this re-organises to form multihexamer chains that will have a long residence time at the injection depot. With the gradual diffusion of zinc, however, these chains are expected to gradually disassemble to release monomers from the terminal ends of multihexamers since the zinc ions of the terminal ends are exposed due to their $\mathrm{T}_{3}$ conformation (Fig. 5). Further studies are required to investigate the kinetics of the multihexamer dissociation process in vivo as the rate-limiting step in the absorption of insulin degludec from the subcutaneous depot into the circulation. In contrast to other basal insulins, the release of monomers would become the rate-limiting step in absorption rather than, e.g. depot blood flow, and this might limit
Fig. 5 Schematic representation of the hypothesis for the mode of retarded absorption of insulin degludec: Insulin degludec is injected subcutaneously as a zinc phenol formulation containing insulin degludec dihexamer in the $T_{3} R_{3}$ conformation. Rapid loss of phenol changes the degludec hexamers to $T_{6}$ configuration and multi-hexamer chains form. With slow diffusion of zinc, these chains break down into dimers, which quickly dissociate into readilyabsorbed monomers.

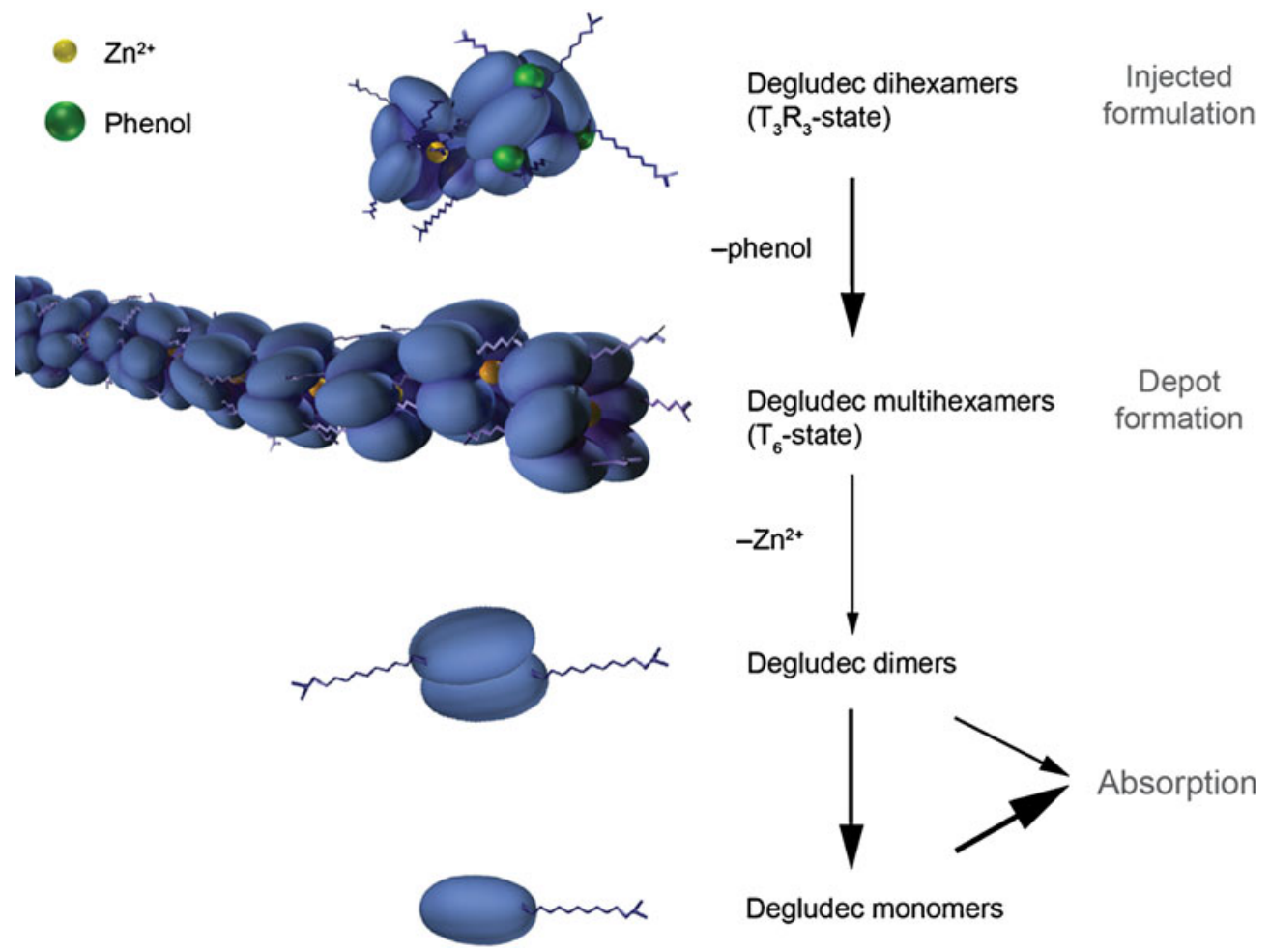


variability in PD response. Furthermore, the affinity for albumin is likely to buffer any variability that does occur in absorption rate through the mechanisms described previously for insulin detemir by Kurtzhals (31). Indeed, the glucose-lowering variability profile of degludec has been shown to be superior to that of insulin glargine (32).

The pharmacological consequence of this protraction mechanism in terms of the time-action profile are shown by PK and PD data $(24,33,34)$. These demonstrate that in clinical use, insulin degludec has a duration of blood-glucose lowering action that extends beyond $42 \mathrm{~h}$ (33), and hence insulin degludec reaches steady-state with daily dosing to produce a flat and stable PK/PD profile $(24,34)$. Clinical results obtained so far show that the ultra-long and flat action profile of insulin degludec can offer greater flexibility of dosing and a reduced risk of nocturnal hypoglycaemia compared to other basal insulins $(28,29,35)$.

\section{CONCLUSION}

In conclusion, it is possible to engineer insulin analogues that can self-associate into a multihexameric state after injection. This was accomplished by attaching a C16 or C18 dicarboxylic acid via a $\gamma$-glutamic acid spacer to the $\varepsilon$-amino group of the B29 lysine residue of desB30 human insulin. As shown herein, this capability is critically dependent on the specific composition of the fatty acid and spacer complex, and therefore shared by few insulin analogues. The resultant PD profile of this mechanism is highly promising from the perspective of developing an improved basal insulin fulfilling the criteria of more than 24-hour duration of action with little variability over the day and from day-to-day, and providing an option for co-formulation with rapid-acting insulin.

\section{ACKNOWLEDGMENTS \& DISCLOSURES}

We thank Dr C. E. Stidsen for the serum albumin measurements. C. Ljørring, B.B. Hansen, L. G. Andersen, B.D. Spon and R. Dyrnesli are thanked for expert technical assistance. We are grateful for the assistance of M. Edmunds, Watermeadow Medical, Witney, UK, in the drafting of this manuscript, funded by Novo Nordisk A/S, Denmark.

All authors are employees of Novo Nordisk A/S, Denmark. Novo Nordisk A/S was the source of all funding in this study.

Open Access This article is distributed under the terms of the Creative Commons Attribution License which permits any use, distribution, and reproduction in any medium, provided the original author(s) and the source are credited.

\section{REFERENCES}

1. Lindholm A. New insulins in the treatment of diabetes mellitus. Best Pract Res Clin Gastroenterol. 2002;16(3):475-92.

2. Blundell TL, Cutfield JF, Cutfield SM, Dodson EJ, Dodson GG, Hodgkin DC, Mercola DA. Three-dimensional atomic structure of insulin and its relationship to activity. Diabetes. 1972;21(2 Suppl):492-505.

3. Brange J, Ribel U, Hansen JF, Dodson G, Hansen MT, Havelund S, Melberg SG, Norris F, Norris K, Snel L, Sorensen AR, Voigt HO. Monomeric insulins obtained by protein engineering and their medical implications. Nature. 1988;333:679-82.

4. Havelund S, Plum A, Ribel U, Jonassen I, Volund A, Markussen J, Kurtzhals P. The mechanism of protraction of insulin detemir, a long-acting, acylated analog of human insulin. Pharm Res. 2004;21:1498-504.

5. Heise T, Nosek L, Rønn BB, Endahl L, Heinemann L, Kapitza C, Draeger E. Lower within-subject variability of insulin detemir in comparison to $\mathrm{NPH}$ insulin and insulin glargine in people with type 1 diabetes. Diabetes. 2004;53(6):1614-20.

6. Heise T, Pieber TR. Towards peakless, reproducible and long-acting insulins. An assessment of the basal analogues based on isoglycaemic clamp studies. Diabetes Obes Metab. 2007;9(5):648-59.

7. DeVries JH, Nattrass M, Pieber TR. Refining basal insulin therapy: what have we learned in the age of analogues? Diabetes Metab Res Rev. 2007;23(6):441-54.

8. Krüger P, Gilge G, Cabuk Y, Wollmer A. Cooperativity and intermediate states in the $\mathrm{T}$ R-structual transformation of insulin. Biol Chem Hoppe-Seyler. 1990;371:669-73.

9. Kaarsholm NG, Ko HC, Dunn MF. Comparison of solution structural flexibility and zinc binding domains for insulin, proinsulin, and miniproinsulin. Biochemistry. 1989;28(10):4427-35.

10. Jonassen I, Havelund S, Ribel U, Plum A, Loftager M, Hoeg-Jensen T, Volund A, Markussen J. Biochemical and physiological properties of a novel series of long-acting insulin analogs obtained by acylation with cholic acid derivatives. Pharm Res. 2006;23:49-55.

11. Jonassen I, Hoeg-Jensen T, Havelund S, Ribel-Madsen U, Tagmose TM, Madsen P. New insulin derivative comprising a naturally occurring insulin with a side chain attached to the alpha-amino or epsilonamino in the B chain of the parent insulin, useful in composition for treating diabetes. Patent registered by Novo Nordisk A/S and published in the Derwent World Patents Index (DWPI). Patent no. WO2005012347-A2.

12. Jorgensen KH. LarsenUD. Homogeneous mono-125I-insulins. Preparation and characterization of Mono-125I-(Tyr A14)- and Mono-125I-(Tyr A19)-insulin. Diabetologia. 1980;19:546-54.

13. Kruger P, Gilge G, Cabuk Y, Wollmer A. Cooperativity and intermediate states in the T;R-structural transformation of insulin. Biol Chem Hoppe Seyler. 1990;371:669-73.

14. Olsen HB, Kaarsholm NC. Structural effects of protein lipidation as revealed by Lys(B29)-myristoyl, des(B30) insulin. Biochemistry. 2000;39:11893-900.

15. Andrews P. Estimation of molecular size and molecular weights of biological compounds by gel filtration. Methods Biochem Anal. 1970;18:1-53.

16. Kurtzhals P, Ribel U. Action profile of cobalt(III)-insulin. A novel principle of protraction of potential use for basal insulin delivery. Diabetes. 1995;44(12):1381-5.

17. Perlmann GE, Longsworth LG. The specific refractive increment of some purified protein. J Am Chem Soc. 1948;70:2719-24.

18. Wen J, Arakawa T, Philo JS. Size-exclusion chromatography with on-line light-scattering, absorbance, and refractive index detectors for studying proteins and their interactions. Anal Biochem. 1996;240:155-66. 
19. Theisen A, Johann C, Deacon MP, Harding SE. Refractive increment data-book. Nottingham: Nottingham University Press; 2000.

20. Kurtzhals P, Havelund S, Jonassen I, Kiehr B, Ribel U, Markussen J. Albumin binding of insulins acylated with fatty acids: characterization of the ligand-protein interaction and correlation between binding affinity and timing of the insulin effect in vivo. Biochem J. 1995;312:725-31

21. Burchard W, Schmidt M, Stockmeyer WH. Information on polydispersity and branching from combined quasi-elastic and integrated scattering. Macromolecules. 1980;13:1265.

22. Choi WE, Brader ML, Aguilar V, Kaarsholm NC, Dunn MF. The allosteric transition of the insulin hexamer is modulated by homotropic and heterotropic interactions. Biochemistry. 1993;32 (43):11638-45.

23. Klein O, Lynge J, Endahl L, Damholt B, Nosek L, Heise T. Albuminbound basal insulin analogues (insulin detemir and NN344): comparable time-action profiles but less variability than insulin glargine in type 2 diabetes. Diabetes Obes Metab. 2007;9(3):290-9.

24. Heise T, Hövelmann U, Nosek L, Bøttcher SG, Granhall C, Haahr H. Insulin degludec has a two-fold Longer Half-life and a more consistent pharmacokinetic profile than insulin glargine. Diabetes. 2011;60 Suppl 1:LB11.

25. den Engelsmann J, Garidel P, Smulders R, Koll H, Smith B, Bassarab S, Seidl A, Hainzl O, Jiskoot W. Strategies for the assessment of protein aggregates in pharmaceutical biotech product development. Pharm Res. 2011;28:920-33.

26. Baker MP, Reynolds HM, Lumicisi B, Bryson CJ. Immunogenicity of protein therapeutics: the key causes, consequences and challenges. Self Nonself. 2010;1(4):314-22.

27. Rosenberg AS. Effects of protein aggregates: an immunologic perspective. AAPS J. 2006;8(3):E501-7.
28. Birkeland KI, Home PD, Wendisch U, Ratner RE, Johansen T, Endahl LA, Lyby K, Jendle JH, Roberts AP, DeVries JH, Meneghini LF. Insulin degludec in type 1 diabetes: a randomized controlled trial of a new-generation ultra-long-acting insulin compared with insulin glargine. Diabetes Care. 201 1;34(3):661-5.

29. Zinman B, Fulcher G, Rao PV, Thomas N, Endahl LA, Johansen T, Lindh R, Lewin A, Rosenstock J, Pinget M, Mathieu C. Insulin degludec, an ultra-long-acting basal insulin, once a day or three times a week versus insulin glargine once a day in patients with type 2 diabetes: a 16-week, randomised, open-label, phase 2 trial. Lancet. 2011;377(9769):924-31.

30. Heise T, Tack CJ, Cuddihy R, Davidson J, Gouet D, Liebl A, Romero E, Mersebach H, Dykiel P, Jorde R. A new-generation ultra-long-acting basal insulin with a bolus boost compared with insulin glargine in insulin-naive people with type 2 diabetes: a randomized, controlled trial. Diabetes Care. 2011;34(3):669-74.

31. Kurtzhals P. How to achieve a predictable basal insulin? Diabetes Metab. 2005;31(4 Pt 2):4S25-33.

32. Heise T, Hermanski L, Nosek L, Feldmann A, Rasmussen S, Stryhn TK, Haahr H. Insulin degludec: less pharmacodynamic variability than insulin glargine under steady state conditions. Diabetologia. 2010;53(Suppl1):S387.

33. Kurzhals P, Heise T, Strauss HM, Bøttcher SG, Granhall C, Haahr H, Jonassen I. Multi-hexamer formation is the underlying mechanism behind the ultra-long glucose-lowering effect of insulin degludec. Diabetes. 2011;60 Suppl 1:LB12.

34. Nosek L, Heise T, Bøttcher SG, Hastrup H, Haahr H. Ultra-longacting insulin degludec has a flat and stable glucose-lowering effect. Diabetes. 2011;60 Suppl 1:LB14.

35. Simon AC, Devries JH. The future of basal insulin supplementation. Diabetes Technol Ther. 2011;13 Suppl 1:S103-8. 